\title{
Mesangial cells, specialized renal pericytes and cytomegalovirus infectivity: Implications for HCMV pathology in the glomerular vascular unit and post- transplant renal disease
}

\author{
Waldemar Popik ${ }^{1}$, Hernan Correa ${ }^{2}$, Atanu Khatua ${ }^{4}$, David M Aronoff ${ }^{2,3}$ and Donald J Alcendor ${ }^{4 *}$ \\ ${ }^{1}$ Department of Internal Medicine and 4Department of Microbiology and Immunology, Center for AIDS Health Disparities Research, Meharry Medical College, \\ School of Medicine, 1005 Dr. D.B. Todd Jr. Blvd., Nashville, Tennessee 37208-3599 USA \\ ${ }^{2}$ Department of Pathology, Microbiology, and Immunology, Vanderbilt University, Nashville, Tennessee, USA \\ ${ }^{3}$ Division of Infectious Diseases, Department of Medicine, and Department of Pathology, Microbiology, and Immunology, Vanderbilt University Medical Centre, \\ Nashville, Tennessee 37232, USA \\ ${ }^{4}$ Meharry Medical College, School of Medicine, Centre for AIDS Health Disparities Research, 1005 Dr. D.B. Todd Jr. Blvd., Nashville, Tennessee 37208-3599, \\ USA
}

\begin{abstract}
Background: Human Cytomegalovirus (HCMV) infection is problematic after kidney transplantation. Human mesangial cells along with human glomerular endothelial cells and podocytes constitute the renal glomerular vascular unit (GVU). HCMV infection of the GVU is poorly understood.

Methods: GVU cells infectivity was analysed by microscopy and immunofluorescence. Cytokines profiles were measured by Luminex assays. Renal tissue analysis for HCMV infection was performed by immunohistochemistry.

Results: Mesangial cells and glomerular endothelial cells but not podocytes were permissive for both lab adapted and clinical strains of HCMV. Luminex analysis of cytokines expressed by mesangial cells exposed to the SBCMV clinical strain was examined. A Tricell infection model of the GVU maintains $>90 \%$ viability with a unique cytokine profile. Finally, we show $\alpha \mathrm{SMA}$ stained mesangial cells permissive for HCMV in renal tissue from a transplant patient.
\end{abstract}

Conclusions: HCMV infection of mesangial cells induces angiogenic and proinflammatory cytokines that could contribute to glomerular inflammation.

\section{Abbreviations}

aSMA: alpha smooth muscle actin; B2-m: Beta-2 microglobulin; BBB: blood brain barrier; CCD: charge-coupled device camera; CD68 cluster designation 68 macrophage marker; CMV: cytomegalovirus; C3: complement component; DAB: 3,3-diaminobenzidine; DAPI: 4',6-diamidino-2-phenylindole; ECM: endothelial cell medium; FITC: fluorescein isothiocyanate; GFP: green fluorescent protein; GMCSF: granulocyte macrophage colony-stimulating factor; GVU: glomerular vascular unit; HCMV: human cytomegalovirus; IHC: immunohistochemistry; IL: interleukin; interleukin-6: IL-6; interleukin-8: IL-8; ITS: insulin-transferrin-selenium; KTR: kidney transplant recipients; L-selectin: cell adhesion molecule found on lymphocytes; monoclonal antibody to human cytomegalovirus major immediate early proteins 1 and 2; MMP-3: matrix metalloproteinase-3; MCP-1: monocyte chemotactic protein-1; MIE 1 and 2: human cytomegalovirus major immediate early gene/proteins 1 and 2; MIP-1 a: macrophage inflammatory protein-1; MOI: multiplicity of infection; NG2: neuron-glial antigen 2; pp28: human cytomegalovirus phosphorylated nuclear protein expressed at late times during virus replication; pp65: human cytomegalovirus phosphorylated envelop protein expressed at late times during virus replication; RANTES: regulated upon activation normal $\mathrm{T}$ cell expressed and presumably secreted; RPMI: Roswell Park Memorial Institute-1640 medium; SBCMV: primary HCMV isolate from a patient; TNF-alpha: tumor necrosis factoralpha; VCAM-1: vascular cell adhesion molecule 1; VEGF: vascular endothelial cell growth factor; vWF: von Willebrand factor.

\section{Background}

Human Cytomegalovirus (HCMV) is the most threatening viral pathogen after kidney transplantation [1,2]. HCMV is a leading cause of post-transplant morbidity and mortality [3]. Clinical manifestations of HCMV disease include myelosuppression, fever, retinitis, pneumonia, colitis, and hepatitis [4]. There is both reduced graft and patient survival

*Correspondence to: Donald J Alcendor, Meharry Medical College, School of Medicine, Centre for AIDS Health Disparities Research, 1005 Dr. D.B. Todd Jr. Blvd., Nashville, Tennessee 37208-3599, USA, Tel: (615) 327-6449, Fax: (615) 327-6929; E-mail: dalcendor@mmc.edu

Key words: cytomegalovirus, pericytes, mesangial cells, podocytes, glomerular endothelial cells, cytokines, inflammation, glomerular vascular unit

Received: April 30, 2018; Accepted: May 21, 2018; Published: May 24, 2018 
after HCMV infection of kidney allograft transplant patients as well as increased risk of graft rejection and increased susceptibility to other opportunistic infections [4-7].

In the absence of HCMV prophylaxis, $40 \%-100 \%$ of all kidney transplant recipients (KTRs) will become infected with HCMV and up to $67 \%$ will develop HCMV clinical disease. In the presence of HCMV prophylaxis, the incidence is reduced but up to $37 \%$ of KTRs will develop HCMV disease [8]. Risk factors for HCMV disease in KTR that most often occur in the first 100 days post-transplant include kidney-pancreas transplantation, type of immunosuppressive drugs used, serostatus of the donor and recipient, presence of absence of acute rejection, donor age $>60$ years, and impaired graft function [9-11]. There are case reports of mesangial sclerosis in HCMV infected patients with congenital nephrotic syndrome. Upon renal biopsy they observed diffuse mesangial sclerosis cytomegalic inclusion in both tubular cells and glomeruli [12]. Ortmanns et al., observed cytomegalovirus infection of mesangial cells in patients with IgA nephropathy. Treatment of cytomegalovirus infection with ganciclovir resulted in remission of IgA nephropathy [13]. It has been reported that primary human mesangial cells, human glomerular epithelial, tubular epithelial, and endothelial cells are permissive for HCMV infection [14-16]. However, these studies were limited primarily to comparative analysis of viral infectivity. To date, mesangial cells, and their contribution to HCMV infection in the glomerulus is poorly understood. The molecular crosstalk between mesangial cells, podocytes, and glomerular endothelial cells, that we refer to as the glomerular vascular unit (GVU), during HCMV infection is also poorly understood. In this study, we examine the GVU for HCMV infectivity, replication kinetics and temporal cytokines expression profiles in a tricell culture model of glomerulus.

\section{Methods}

\section{Renal tissue}

Renal biopsy tissue from a HCMV infected renal transplant patient was obtained via collaboration with Dr. Gary Hayward at The Johns Hopkins University Medical Centre. These studies were approved by the Johns Hopkins Institutional Review Board (IRB). Disseminated HCMV infection in renal tissue was confirmed by a pathologist and subsequently reconfirmed by IHC staining for the HCMV major immediate early (MIE) and the pp28 HCMV phosphorylated nuclear proteins [17]. Tissue was formalin fixed and paraffin embedded, and 5 -micron sections were placed on chemate slides for dual-labelled IHC staining [18].

\section{Cells and viruses}

The primary isolate (termed SBCMV) was provided by Dr. Ravit Arav-Boger, Johns Hopkins University, as previously described [19]. The IRB exemption for the use of this isolate was given by Johns Hopkins Hospital. The HCMV-GFP recombinant virus was obtained from Dr. Gary Hayward, Johns Hopkins University. The SBCMV clinical isolate,

Toledo lab-adapted strain of HCMV, and HCMV-GFP recombinant virus were cultivated separately in human foreskin fibroblasts with DMEM (containing $4.5 \mathrm{~g} / \mathrm{l}$ D-glucose, $584 \mathrm{mg} / \mathrm{l} \mathrm{L}$-glutamine and $3.7 \mathrm{~g} / \mathrm{l}$ sodium bicarbonate, Gibco BRL, USA). All infections with the SBCMV clinical strain were performed at passage level 3. Primary human renal mesangial cell and renal glomerular endothelial cells were obtained from ScienCell (Carlsbad, CA) and cultivated in mesangial cell medium $(\mathrm{MCM})$ and endothelial cell media (ECM) from ScienCell, respectively. Mesangial cells and renal glomerular endothelial cells were maintained at passage level 3. Human glomerular podocytes were obtained from Dr.
Moin A. Saleem and were cultured as described [20,21]. All cells were trypsinized and plated on uncoated $4.2 \mathrm{~cm} 2 /$ well glass chamber slides at density $2.5 \times 105$ cells per well. Heat- killed SBCMV was prepared by heating the viral inoculum to $65^{\circ} \mathrm{C}$ for $30 \mathrm{~min}$ in a water bath [22]. The mild heat inactivation that we employ is unlikely to cause a global effect on thermolabile viral proteins.

\section{Cytomegalovirus infection of mesangial cells, renal microvascular endothelial cells, and podocytes}

Mesangial cells, renal microvascular endothelial cells, and podocytes were infected with SBCMV, Toledo HCMV, or HCMV GFP at a multiplicity of infection (MOI) of 0.1. Virus adsorption was allowed for $3 \mathrm{~h}$ and the infectious inoculum was removed and replaced with fresh medium. Mock-infected cells included medium only with no virus along with heat-killed virus controls. For virus replication kinetics in mesangial cells, glomerular endothelial cells, and podocytes, infections were performed in triplicate in multi-well chamber slides as previously described [19].

\section{Immunofluorescence}

Immunofluorescent staining was performed as previously described [19]. Briefly, chamber slide cultures containing SBCMVinfected or mock-infected human renal mesangial cells (HRMC), human renal glomerular endothelial cells, and podocytes were washed twice with PBS pH 7.4, air dried, and fixed in absolute methanol for 10 minutes. Cells were air dried for 15 minutes, hydrated in Tris buffered saline ( $\mathrm{pH}$ 7.4) for $5 \mathrm{~min}$, and incubated separately for $1 \mathrm{~h}$ with monoclonal antibodies. The antibodies included NG2P (Millipore, Darmstad, Germany) and the following from Santa Cruz Biotechnology (Santa Cruz, CA, USA): vimentin, CD68, fibronectin, podocalyxin, von Williebrand factor, and aSMA all diluted 1:50 in PBS $\mathrm{pH}$ 7.4. For HCMV infection of human renal mesangial cells (HRMC), human renal glomerular endothelial cells, and podocytes, cells were incubated for $1 \mathrm{~h}$ with monoclonal antibodies to HCMV-MIE (MIE, MAB810, Millipore) and the HCMV viral tegument protein pp65 (UL83, Vector Laboratories, Burlingame, CA) or the late virion tegument protein pp28 (Santa Cruz Biotech), all at a 1:50 dilution in $\mathrm{PBS} \mathrm{pH}$ 7.4. Immunofluorescent staining was performed as previously described [19].

\section{Glomerular vascular unit tricell infection model}

The GVU model, composed of primary mesangial cells, glomerular endothelial cells, and podocytes was established in chamber slides at a ratio mesangial/endothelial/podocyte of 3:2:1, respectively. The rationale for the $3: 2: 1$ ratio is supported by findings in the glomerulus of the rat and the finding that pericyte density (with the exception of the brain and retina) are found to be lower in other vascular beds [23].

However, the exact ratio of mesangial cells, glomerular endothelial cells, and podocytes associated with the glomerular vasculature specifically is unknown.

Cell population ratios during tricell cultivation can change; therefore, we consistently use these primary cells at the same passage level and the initial cultivations are performed with media recommended by the manufacturer. Podocytes were initially cultivated in complete RPMI supplemented with insulin-transferrin-selenium (ITS) media to $80 \%$ confluence at a cell density $2.5 \times 104$ due to slow growth kinetics. Mesangial cells, initially cultivated at the same cell density in mesangial cell medium (ScienCell), were added and the mixture cultivated in RPMI-ITS. After $24 \mathrm{~h}$, renal endothelial cells 
cultivated in ECM at the desired density were added to complete the tricell mixture with all three cell types growing in 60/40 ratio of RPMI-ITS and ECM medium. The tricell mixture was then infected for $96 \mathrm{~h}$ with SBCMV at a MOI of 0.1 . The tricell mixture was stained for live/dead cell viability, using an assay kit (Life Technologies, Grand Island, NY).

\section{Immunohistochemistry}

Archived renal tissue was dual-labeled by IHC stained for HCMVMIE, HCMV tegument protein (pp28), and alpha smooth muscle actin (aSMA; a pericyte marker) as previously described [19].

\section{Luminex analysis}

The inflammatory and angiogenic cytokine analysis was performed with $200 \mu \mathrm{l}$ of supernatant from 3 pooled cultures of mock-infected, SBCMV-infected, and heat-killed SBCMV exposed mesangial cells for $24 \mathrm{~h}$ and $96 \mathrm{~h}$ post-exposure using a Luminex instrument (Luminex Corporation, Austin, TX) and 100-plate viewer software. Luminex analysis was performed on supernatants as previously described [19]. Infections were

performed in triplicate in chamber slides for 24 , and $96 \mathrm{~h}$. Replicate assays are inherent in the Luminex technology by counting 50 bead replicates per analyte and reporting the median. This is the equivalent of running 50 replicate assays per well. In addition, robotic pipetting was performed for all volume-critical steps, which minimizes wellto-well variability, and calibrators and controls were run in duplicate involving 3 levels of control per analyte in duplicate on every plate [24].

\section{Cell viability assays}

The Tricell mixture was stained for viability using a live/dead cell viability assay kit (Life Technologies, Grand Island, NY).

\section{Statistical analysis}

Experiments presented in this study that involved replication kinetics with the GFP-HCMV recombinant virus were performed in triplicate. Supernatants from mock infected, SBCMV infected, and heat-killed SBCMV exposed mesangial cells were separately taken from triplicate samples and pooled for Luminex analysis. A P-value of $<0.05$ was considered statistically significant.

\section{Results}

\section{Expression profiles of human renal mesangial cell}

Primary human renal mesangial cells show expected morphological characteristics of normal mesangial cells that are clearly visible in sub confluent and confluent cultures (Figure 1A and 1B). We examined biomarker expression of normal primary renal mesangial cells by immunofluorescent staining. We observed that mesangial cells express characteristic pericyte markers including NG2 proteoglycan, vimentin, CD68, and fibronectin, respectively (Figure 1C,1D,1E and 1F) [19]. Isotype controls antibodies for NG-2P, Vimentin, CD68 and fibronectin stain negative with mesangial cells (Figure 2G,2H,2I and 2J).

Human renal mesangial cells and human renal glomerular endothelial cells are permissive for HCMV infection but not podocytes

Mesangial cells show similar morphological characteristics of brain vascular pericytes, with long extension of the cytoplasm that are more visible in sub confluent cultures (Figure 2A). However, when confluent they appear fibroblastic in morphology. Using a low MOI of 0.1 with
Primary Human Renal Mesangial Cells Expressing Pericyte Biomarkers

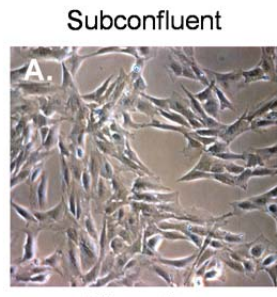

Vimentin

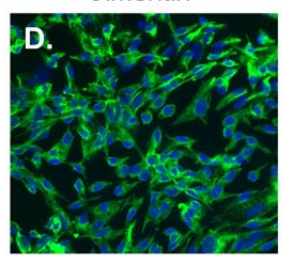

NG-2P isotype cont.

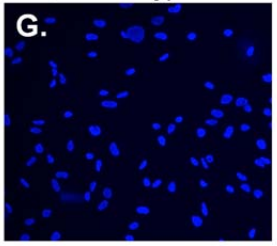

Fibronectin isotype cont

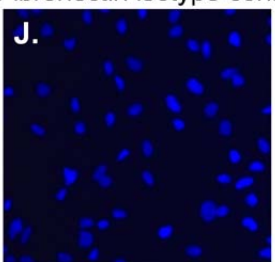

Confluent

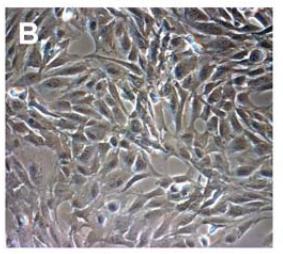

CD68

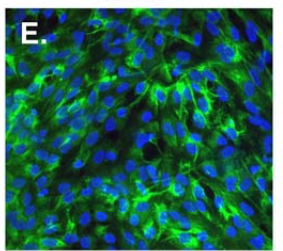

Vimentin isotype cont.

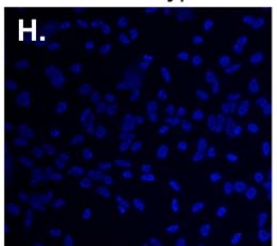

NG-2P

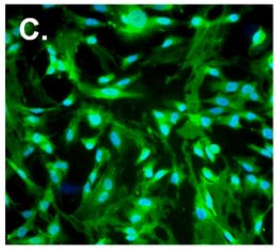

Fibronectin

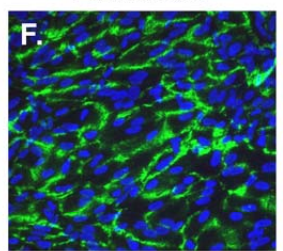

CD68 isotype cont.

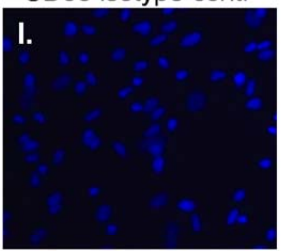

Figure 1. Normal mesangial cells expressing pericyte biomarkers

Phase contrast images of: (A) an uninfected sub confluent monolayer of mesangial cells, (B) a confluent monolayer of mesangial cells and, (C) fluorescent image of mesangial cells staining positive for NG2 proteoglycan, (D) fluorescent image of mesangial cells staining positive for vimentin, (E) fluorescent image of mesangial cells staining positive CD68 and (F) fluorescent image of mesangial cells staining positive fibronectin. All images were taken on a Nikon TE2000S microscope mounted with a charge-coupled device (CCD) camera at 200x magnification. For fluorescent images 4',6-diamidino-2-phenylindole (DAPI) was used to stain the nuclei blue

the HCMV Towne strain and the SBCMV clinical isolate we observe characteristic HCMV cytomegalic cytopathology at 10 days post infection (Figure $2 \mathrm{~B}$ and $2 \mathrm{C}$ ). We demonstrate that mesangial cells are fully permissive for HCMV lytic replication as demonstrated by expression of the HCMV major immediate early (MIE) 1, 2 and the late viral tegument protein pp28 (Figure 2D,E) [25]. Isotype controls for HCMV MIE and pp28 in SBCMV mesangial stain negative (Figure $2 \mathrm{~F}, 2 \mathrm{G})$. Infection of mesangial cells with an HCMV-US28 recombinant virus expressing GFP shows that mesangial cells support HCMV lytic replication with cytomegalic cytopathology at 6 days post infection (Figure 2F).

Human glomerular endothelial cells are more permissive than mesangial cells for laboratory strains of HCMV but not for clinical strains of HCMV

We also examined viral replication kinetics as measured by pp28gfp expression over time monitoring an HCMV time course of infection employing the cellular components of the human glomerular vascular unit (GVU) (Figure 3). Human glomerular podocytes, glomerular endothelial cells, and mesangial cells were infected with the HCMV- 
HCMV Cytopathology in Primary Human Renal Mesangial Cells

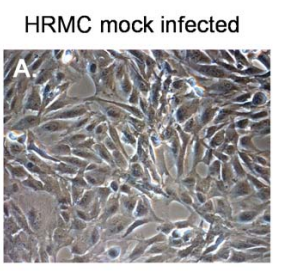

SBCMV immediate early

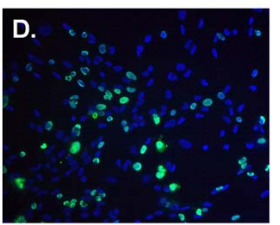

MIE isotype control

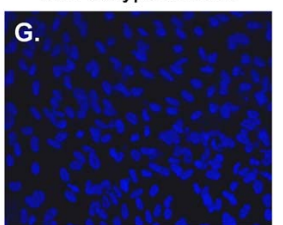

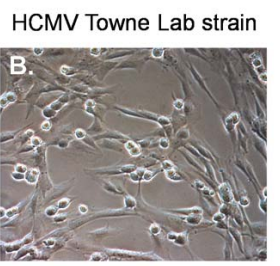

SBCMV pp28 late protein

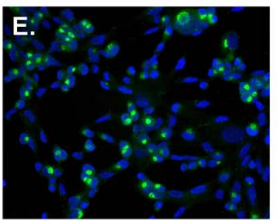

pp28 isotype control

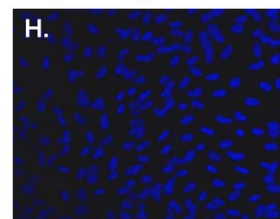

SBCMV Clinical Strain

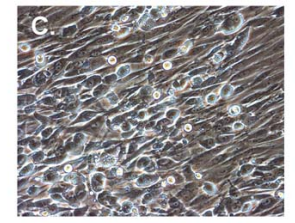

Recombinant HCMV-GFP

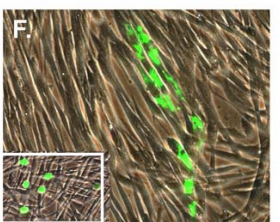

Figure 2. HCMV infectivity of primary human renal mesangial cells

Phase contrast images of: (A) an uninfected sub confluent monolayer of mesangial cells, (B) a confluent monolayer of mesangial cells 10 days after infected the Towne strain of HCMV, and (C) mesangial cells 10 days after infection with the clinical strain SBCMV. Immunofluorescence staining of SBCMV infected mesangial for (D) MIE protein and (E) pp28 virion late protein. (F) Phase fluorescent overlay image of mesangial cells infected with a recombinant HCMV virus expressing GFP. All images were taken on a Nikon TE2000S microscope mounted with a charge-coupled device (CCD) camera at 200x magnification. For fluorescent images, 4',6-diamidino-2-phenylindole (DAPI) was used to stain the nuclei blue

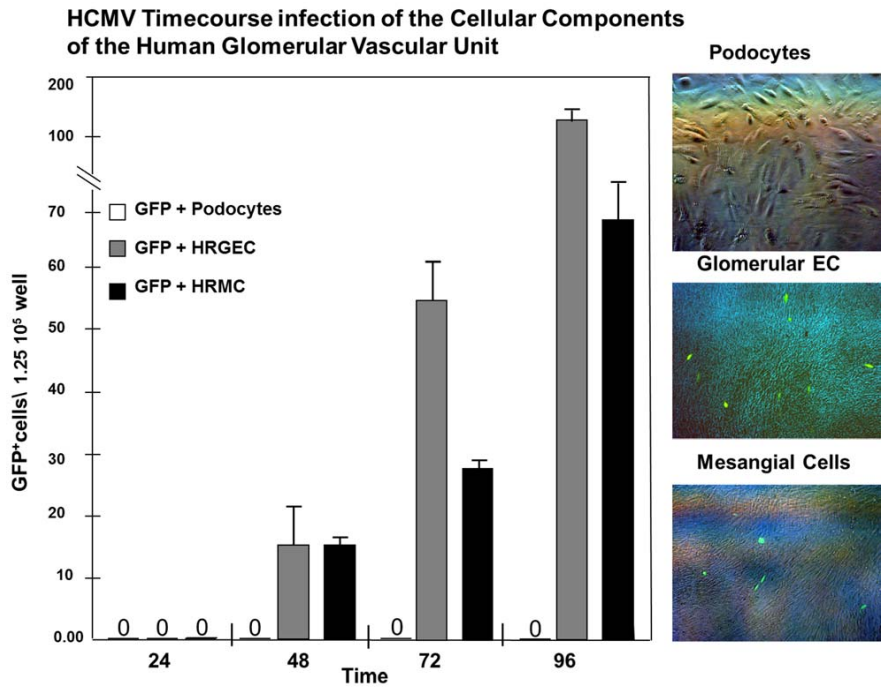

Figure 3. Time course analysis infection of GVU cells with a lab strain of HCMV

Time course analysis of human cytomegalovirus-GFP (HCMV-GFP) infection of GVU (Glomerular Vascular Unit) cells. (A) A graph showing the number of infected HCMVGFP-positive podocytes (open bars), glomerular endothelial cells (gray bars), and mesangial (black bars) per $4 \times 106$ total cells over the time course of 12, 24, 48 and 96 hours post infection. (B) Right panel: phase contrast images of infected podocytes, glomerular endothelial cells, and mesangial cells with a phase fluorescent overlay showing HCMVGFP-positive cells stained green. All images were taken on a Nikon TE2000S microscope mounted with a charge-coupled device (CCD) camera at 200x magnification

US28 recombinant virus expressing GFP at a MOI of 0.1 and GFP positive cells were counted using fluorescent microscopy during a time course of 24, 48, 72, 96 hours after infection (Figure 3). We observed no infection in podocytes with the HCMV-US28 recombinant virus and we observed the highest levels of infection in glomerular endothelial cells compared to mesangial cells with the recombinant virus (Figure 3). We also examined glomerular podocytes, glomerular endothelial cells, and mesangial cells for HCMV infectivity at 96 hours post infection with the SBCMV clinical strain. Again, we observed no infection in podocytes with the clinical strain of HCMV and we observed higher levels of infection of SBCMV infected mesangial cells compared to glomerular endothelial cells, as demonstrated by the number of HCMV MIE positive nuclei observed after immunohistochemical staining (Figure 4).

Dysregulation of angiogenic and proinflammatory cytokines in SBCMV infected mesangial cells at both early and late time post infection

Angiogenic and proinflammatory cytokines levels were examined in mesangial cells exposed to SBCMV for $24 \mathrm{~h}$ (Figure 5). In mesangial cells exposed to SBCMV, we observed increased levels B2-m, ferritin, complement C3, IL-6, IL-7, IL-8, RANTES, TNF- $\alpha$, GMCSF, MCP-1 and MMP-3 when compared to mock infected controls. We observed higher levels of MIP-1 $\alpha$ in mock infected cells compared to SBCMV infected mesangial cells. In mesangial cells exposed to heat-killed virus, we observed higher levels of ferritin and MIP-1a compared to SBCMV infected cells (Figure 5). In SBCMV infected mesangial cells, at $96 \mathrm{~h}$ post infection we observed higher levels of B2-m, ferritin, complement C3, IL-7, IL-8, RANTES, VEGF, and MMP-3 when compared to mock infected controls (Figure 6). We observed higher levels of TNF- $\alpha$, MIP$1 \alpha$, and MCP-1 in mock infected cells compared to SBCMV infected mesangial cells (Figure 6).

\section{SBCMV Infection of the Cellular Components in the Human Glomerular Vascular Unit}
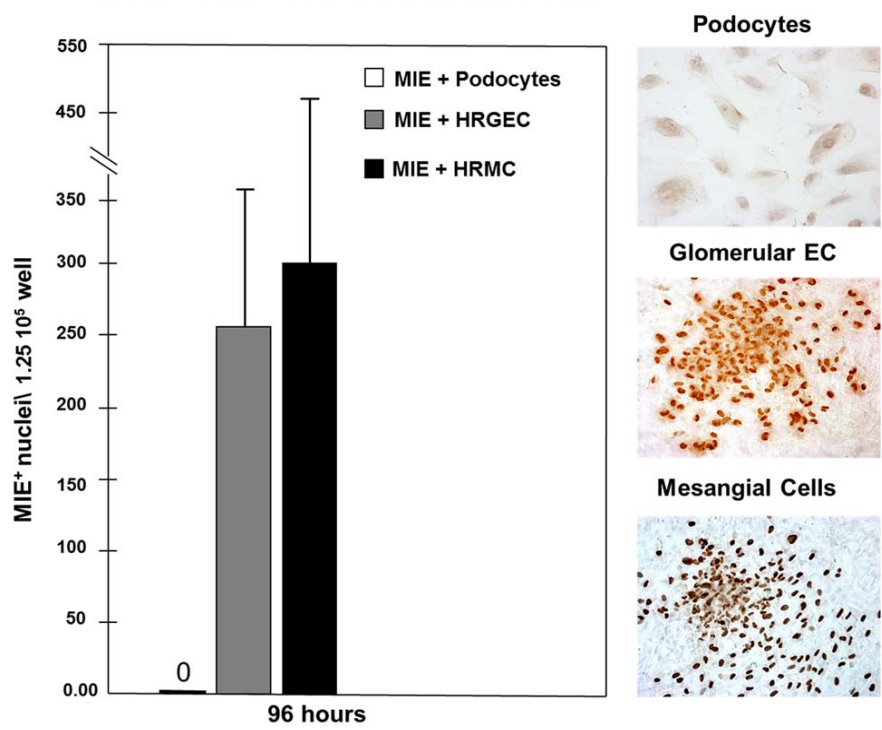

Figure 4. Infection of GVU cells with a clinical strain of HCMV

Infection with the clinical strain (SBCMV) of GVU (Glomerular Vascular Unit) cells 96 hours after infection. (A) A graph showing the number of infected SBCMV positive podocytes (open bars), glomerular endothelial cells (gray bars), and mesangial (black bars) per $4 \times 106$ total cells 96 hours after infection. (B) Right panel: Immunohistochemical stained images of SBCMV infected podocytes, glomerular endothelial cells, and mesangial cells showing SBCMV positive cells (stained brown). All images were taken on a Nikon TE2000S microscope mounted with a charge-coupled device (CCD) camera at 200x magnification 


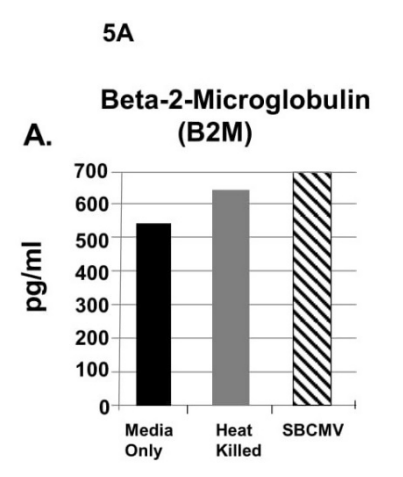

D.

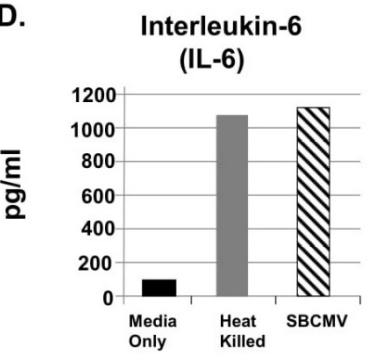

$5 B$.

G.

RANTES

(CCL5)
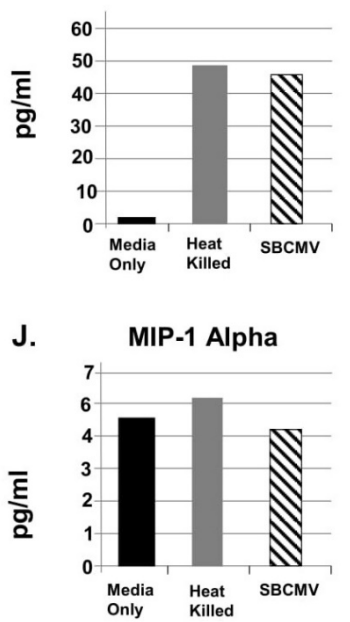

B.

Ferritin

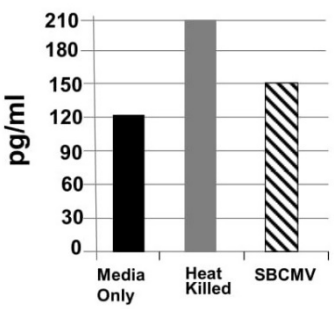

E.

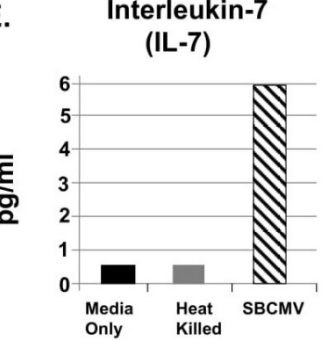

Complement C3

C.
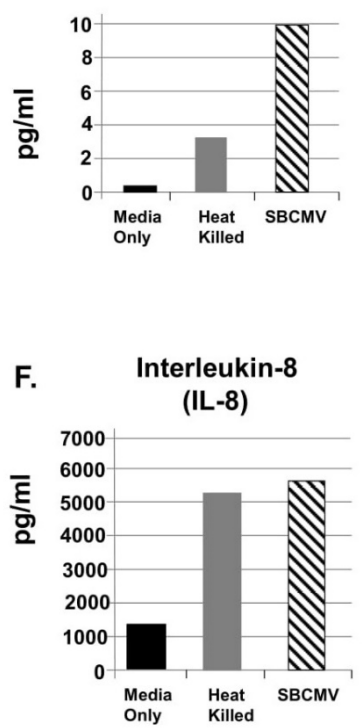

I. GMCSF

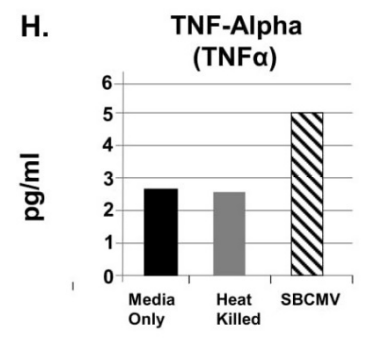

K. Monocyte Chemotactic Protein -1 (MCP-1)

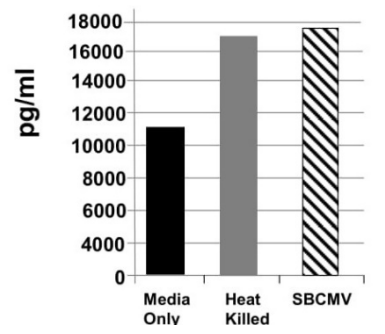

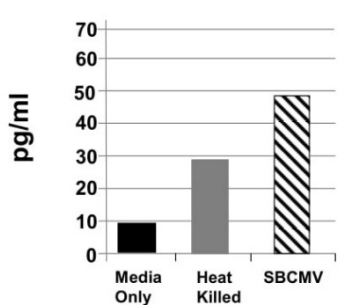

L.

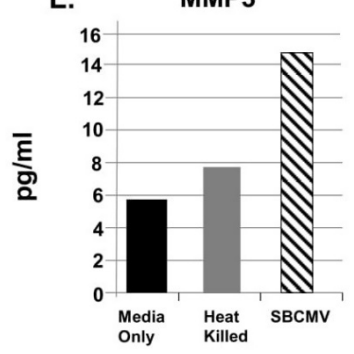

Figure 5. SBCMV induction of proinflammatory and angiogenic cytokines in mesangial cells after 24 hours

Cytokine profiles of SBCMV-infected mesangial cells by Luminex analysis at 24 hours post infection are given. Results from cells exposed to media only are shown as solid black bars, cells exposed to heat-killed SBCMV are shown as gray bars, and results from cells exposed to the SBCMV clinical isolate are shown as stippled black bars. Results are included for (A) B2M, (B) Ferritin, (C) Complement C3, (D) IL-6, and (E) IL-7, (F) IL-8, (G) RANTES, (H) TNF- $\alpha$, (I) GMCSF, (J) MIP-1 $\alpha$, (K) MCP-1, and (L) MMP-3. Results are given in pg/ml. Results shown are the averages of triplicate samples

Proinflammatory and angiogenic cytokines that contribute to glomerulosclerosis are induced after SBCMV infection of a tricell culture model of the glomerular vascular unit

The glomerular vascular unit, composed of podocytes, primary glomerular endothelial cells, and mesangial cells, was employed to develop a tricell culture model of the human glomerulus (Figure 7A-a,7A-b,7A-c). We began by cultivating the podocytes line in RPMI medium supplemented with $10 \%$ insulin-transferrin-selenium (ITS)
(Figure 7B-a), and later we discovered that mesangial cells could be cultivated in RPMI/ITS medium (Figure 7B-b). We then determined that glomerular endothelial cells were more fastidious than either podocytes or mesangial cells and would require endothelial cell medium supplementation with RPMI/ITS medium. We established a ratio of $60 \%$ endothelial cell media and $40 \%$ RPMI/ITS medium for the tricell cultivation (Figure $7 \mathrm{~A}-\mathrm{c}$ ). We achieve $>90 \%$ viability for 8 days in culture (Figure 7A-d). The tricell culture was then exposed to the SBCMV clinical strain, heat killed SBCMV, and mock infected using 
6A

A. Beta-2-Microglobulin

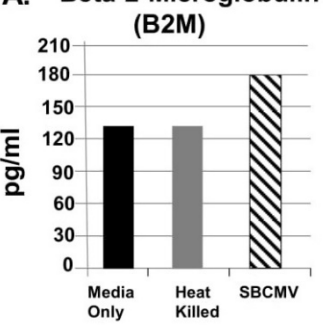

D.

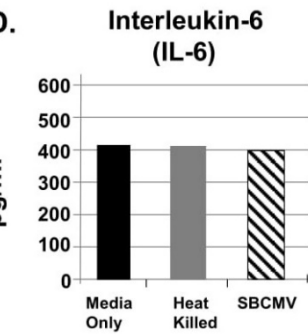

$6 B$.

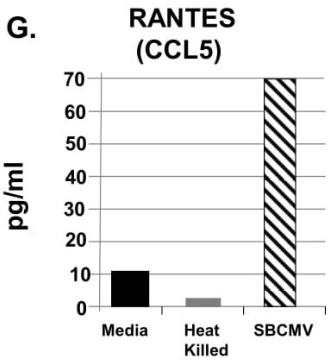

J.

MIP-1 Alpha

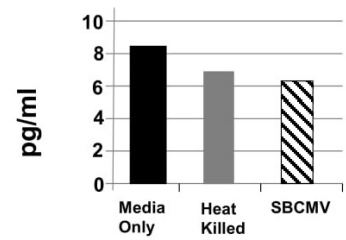

B.

Ferritin

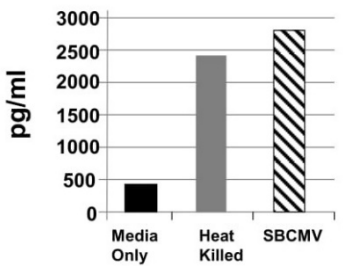

E. Interleukin-7

(IL-7)

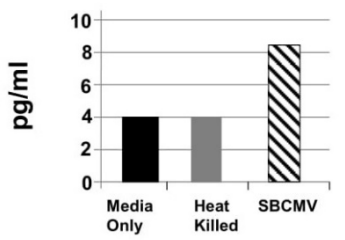

C. Complement $\mathrm{C3}$

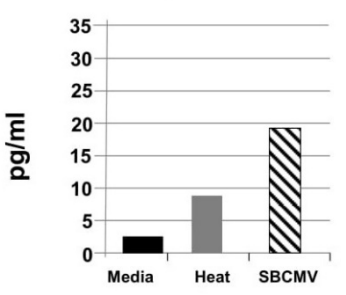

F. Interleukin-8

(IL-8)

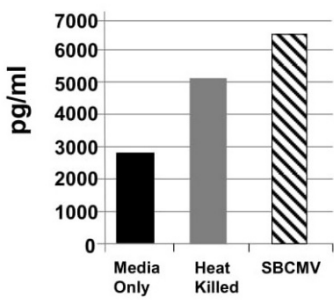

I. VEGF

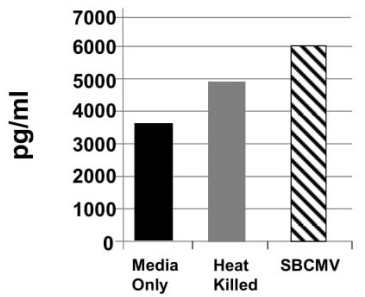

L. MMP3

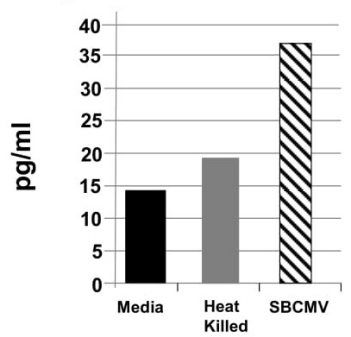

Figure 6. SBCMV induction of proinflammatory and angiogenic cytokines in mesangial cells after 96 hours

Cytokine profiles of SBCMV-infected mesangial cells by Luminex analysis at 96 hours post infection are given. Results from cells exposed to media only are shown as solid black bars, cells exposed to heat-killed SBCMV are shown as gray bars, and results from cells exposed to the SBCMV clinical isolate are shown as stippled black bars. Results are included for (A) B2-m, (B) Ferritin, (C) Complement C3, (D) IL-6, and (E) IL-7, (F) IL-8, (G) RANTES, (H) TNF- $\alpha$, (I) VEGF, (J) MIP-1 $\alpha$, (K) MCP-1, and (L) MMP-3. Results are given in pg/ml. Results shown are the averages of triplicate samples

media only. In the GVU tricell model with cells exposed to SBCMV for $96 \mathrm{~h}$, we observed higher levels of ferritin, complement C3, Alpha-2 macroglobulin, IL-7, IL-1 $\beta$, GMCSF, VEGF, haptoglobin, and MCP1 when compared to mock infected controls (Figure 8A and 8B). We observed higher levels of B2-m, RANTES, and MIP-1 $\alpha$ in mock infected cells compared to SBCMV infected mesangial cells (Figure 8A and 8B). In the tricell GVU model exposed to heat-killed virus, we observed higher levels B2-m, ferritin, complement C3, RANTES, GMCSF, VEGF, and MIP-1 $\alpha$ compared to SBCMV infected cells (Figure 8A and 8B).

After review of the complied Luminex derived cytokine data we observed a $>2$-fold dysregulation of complement C3, IL-7, RANTES MIP-1a, and Haptoglobin when glomerular cells were exposed to wildtype SBCMV and compared to cells exposed to heat- killed SBCMV (Table 1). 


\section{Cellular Components of the Glomerular Vascular Unit}
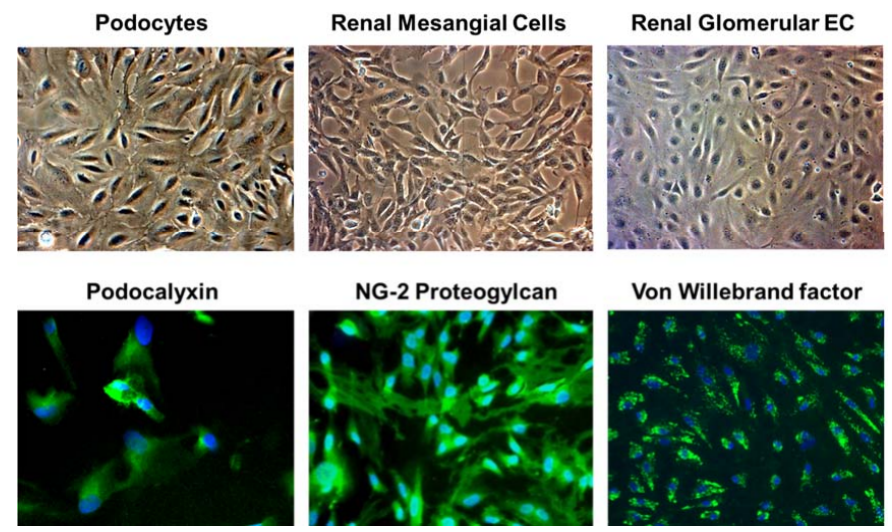

Von Willebrand factor

Cultivation of the Glomerular Vascular Unit Tri-cell Model

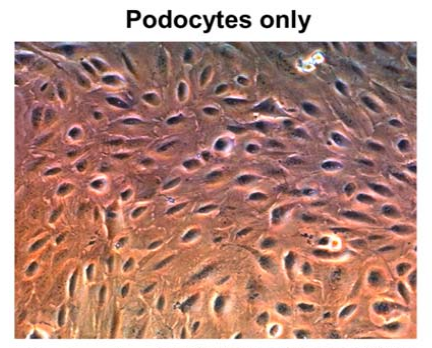

Podocytes+HRMC+HRGEC/GVU

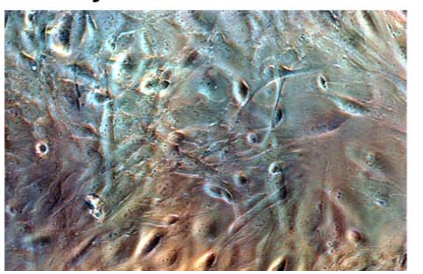

Podocytes and Mesangial Cells

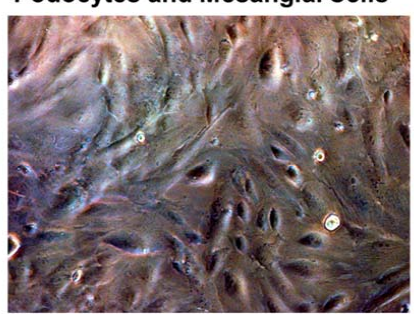

GVU-Tricell culture/>90\% Viability

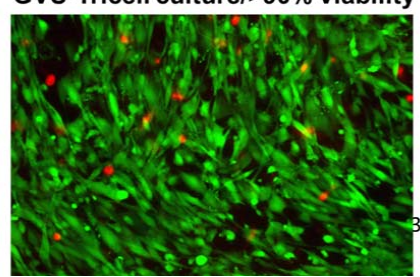

Figure 7. Cultivation of the GUV tricell culture model

Cellular components of the GVU (Glomerular Vascular Unit) cells cultivated and stained are shown. 7A top panel shows phase microscopy images of podocytes, renal glomerular endothelial cells, and mesangial cells. Podocytes, glomerular endothelial cells, and mesangial cells stain positive for podocalyxin, von Willebrand factor, and NG-2 proteoglycan, respectively. 7B bottom panel shows phase images of the steps in cultivation of the GVU tricell model which includes (A) phase image of podocytes only in RMPI/ ITS medium, (B) phase image of podocytes and mesangial cells in RPMI/ITS medium, (C) phase image of podocytes + mesangial cells + glomerular endothelial cells cultured in a $60 \% / 40 \%$ mixture of EC medium and RMPI/ITS medium, (D) dual labeled fluorescent image of live cells (cells staining green) and dead cells (cells staining red). All images were taken on a Nikon TE2000S microscope mounted with a charge-coupled device (CCD) camera at 200x magnification. For fluorescent images, 4',6-diamidino-2- phenylindole (DAPI) was used to stain the nuclei blue

\section{Perivascular cells stain positive for a mesangial biomarker and HCMV in infected vascular tissue from a transplant patient}

Renal tissue from a transplant patient infected with HCMV was stained by dual label immunohistochemistry for mesangial cell biomarkers and viral antigen markers HCMV MIE and the viral tegument late gene protein pp28 (Figure 9). We observed disseminated HCMV infection in the renal tissue for both HCMV MIE and the pp28 antigens (Figure 9A and 9B). We also observed dual staining for smooth muscle actin ( $\alpha$ SMA), a known mesangial cell marker, and HCMV MIE as shown by black arrows (Figure 9C and 9D).

\section{Discussion}

Mesangial cells are pericytes of the kidney that are abluminal to glomerular capillaries and located central to the glomerular tufts between the capillary loops. Mesangial cells synthesize and regulate the mesangial cell matrix and glomerular hemodynamics via cell contraction and release of vasoactive hormones. Mesangial cells have morphological characteristics that are similar to other pericytes and stain positive for reported pericytes antigenic biomarkers NG-2P, vimentin, CD68, and fibronectin $[19,26]$. Mesangial cells, like pericytes of the blood-brain barrier (BBB) and the inner blood retinal barrier (IBRB) previously reported by Alcendor et. al. are permissive for both laboratory adapted and clinical strains of HCMV and were the most permissive target cells in both neurovascular units of the brain and retina [19,26]. SBCMV infection in related cell types the blood brain barrier, blood retinal barrier, and the blood placental barrier we published support the notion that the cell types that are abluminal to endothelial cell of these different microvascular compartments known as pericytes that includes brain pericytes, retinal pericytes, and placental pericytes were all found to be the most permissive cell type for HCMV infection [19,26,27]. Human retinal pericytes were also found to be most permissive for Zika virus when compared to retinal endothelial cells and Müller cell [28]. This finding supports the notion that all vascular pericytes are permissive for HCMV infection no matter the source and that all pericytes support the greatest viral burden, representing amplification reservoirs for HCMV infection and dissemination in their respective vascular beds. Among cellular components of the GUV, we observed that lab adapted strains of HCMV replicate at higher levels in glomerular endothelial cells when compared to mesangial cells, but we show that clinical strains of HCMV replicate at higher levels in mesangial cells when compared to glomerular endothelial cells (Figures 3 and 4). In addition, we observed that cultivation beyond 96 hours produced higher levels of HCMV MIE positive cells and plaque formation at 10 days after infection in mesangial cell compared to human glomerular endothelial cells. Our interest was to examine early events in HCMV replication profile before extensive cytolysis occurred. Evaluation of pp28 positive cell during a time course of infection is a true indication of cells that support a productive infection. For both laboratory adapted and clinical strains of HCMV we find no evidence of HCMV infection in podocytes. We examined HCMV infected podocytes by IFA using antibodies to the major immediate early and find that HCMV infected podocytes stained negative. This would support the notion that there is no abortive infection in podocytes. A report by Rane et al. shows HCMV cytopathology in podocytes and glomerular endothelial cells with no evidence of inflammation in a renal transplant patient [29].

Temporal cytokine expression profiles reveal upregulation of proinflammatory and angiogenic biomarkers in mesangial cells exposed to SBCMV at 24 hours post exposure (Figure 5). We observe upregulation of B2-m in mesangial cells. B2-m levels in serum from renal transplants have been shown to be useful as an early diagnostic marker for HCMV infection [30]. Mesangial cells show upregulation of ferritin compared to mock infected controls. Increases in ferritin levels are proposed as well-suited biomarkers for monitoring renal allograft inflammation after transplantation [31]. Serum ferritin levels greater than $500 \mathrm{ng} / \mathrm{ml}$ have also been associated with increase infections in renal transplant patients [32]. Complement C3 is upregulated in mesangial cells exposed to HCMV compared to mock infected controls. Complement activation has been observed after renal transplantation in the past but is not common due to current HCMV prophylaxis $[33,34]$. In a study by Andresdottir, a primary HCMV infection in a renal transplant patient was associated with the recurrence of membranoproliferative glomerulonephritis also known as C3 glomerulopathy [35]. C3 glomerulopathy is characterized by glomerular disease in renal transplant patients associated with 

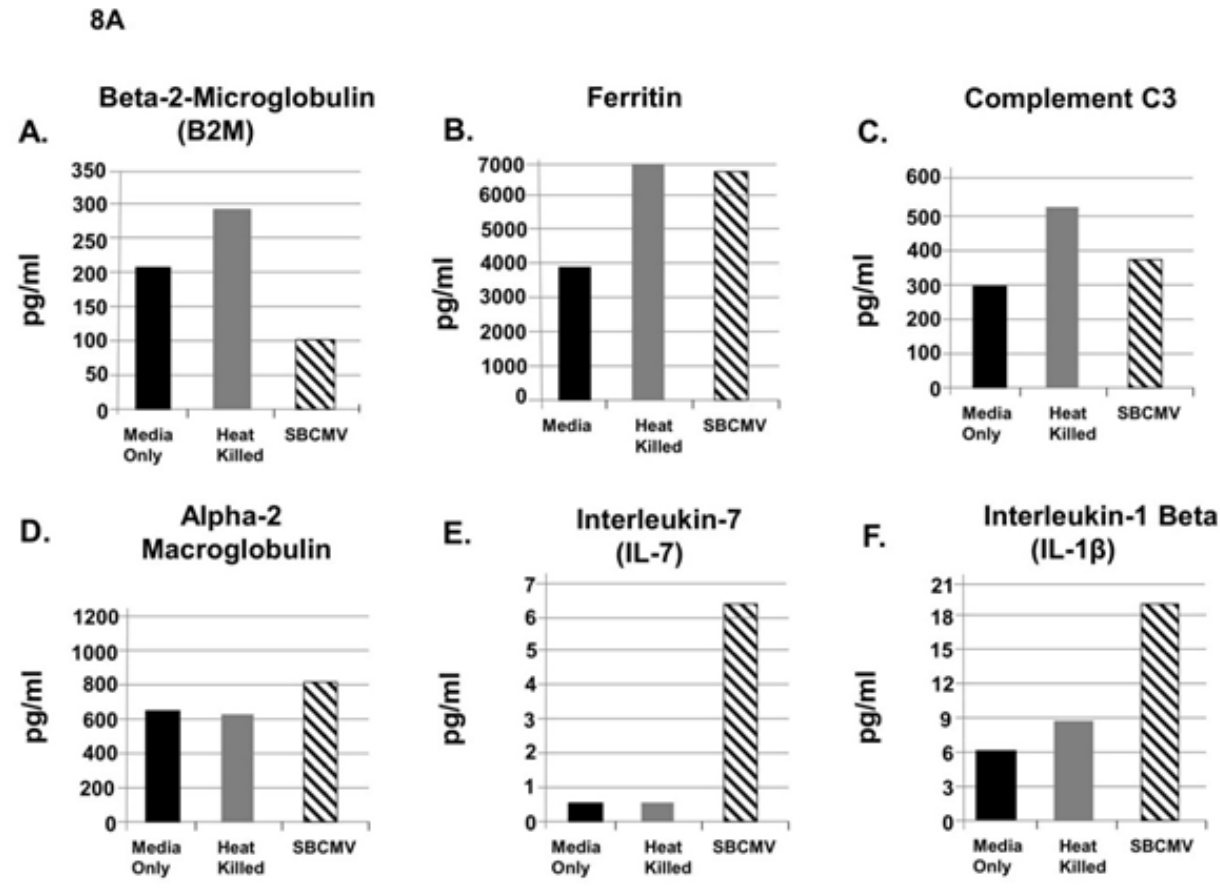

8B
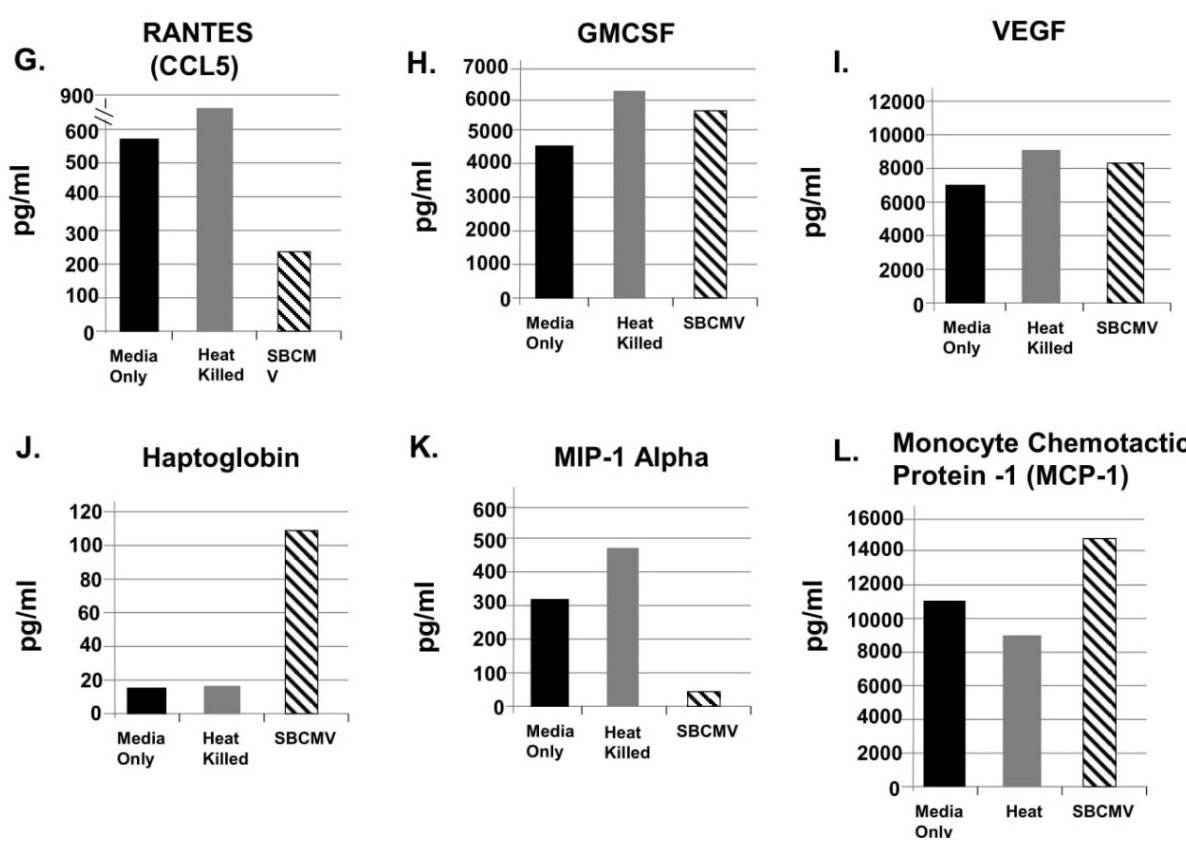

Figure 8. SBCMV induction of proinflammatory and angiogenic cytokines in the glomerular vascular unit (GVU) cells after 96 hours

Cytokine profiles of SBCMV infected GVU (Glomerular Vascular Unit) cells by Luminex analysis at 96 hours post infection are given. Results from cells exposed to media only are shown as solid black bars, cells exposed to heat-killed SBCMV are shown as gray bars and results from cells exposed to the SBCMV clinical isolate are shown as stippled black bars. Results are included for (A) B2-m, (B) Ferritin, (C) Complement C3, (D) alpha 2 macrogobulin, (E) IL-7 (F) IL-8, (G) RANTES (H) GMCSF (I) VEGF, (J) Haptoglobin, (K) MIP-1 $\alpha$, and (L) MCP-1.

Results are given in $\mathrm{pg} / \mathrm{ml}$. Results shown are the averages of triplicate samples

dysregulation of the alternative complement pathway and is also associated with end-stage kidney disease [36]. We observed a 3-fold and 2 -fold increase in the levels of complement C3 in mesangial cells at $24 \mathrm{~h}$ and $96 \mathrm{~h}$ respectively (Table 1 ). Dysfunction of the complement cascade is an underlying cause of several kidney diseases [37]. Renal transplant patients affected by end stage renal disease (ESRD) due to C3 glomerulopathies have high a recurrence rate after renal transplantation and represent an important cause of graft loss [38].
We observed marginal increases IL-6 and IL-8 in mesangial cells exposed to HCMV after 24 hours but we observed a higher level of IL-7 at $24 \mathrm{~h}$ and $96 \mathrm{~h}$ in mesangial cells and in GVU tri-cell culture model $96 \mathrm{~h}$ after exposure to SBCMV.

In a study by Muller et al., renal transplant patients that developed HCMV disease had higher plasma levels of IL-6 and IL-8 when compared patients who did not develop HCMV disease. We observed 
Popik W (2018) Mesangial cells, specialized renal pericytes and cytomegalovirus infectivity: Implications for HCMV pathology in the glomerular vascular unit and post- transplant renal disease

Table 1. Luminex analysis of cytokine/chemokine (C-C) expression levels in mesangial cells and in the GVU tri-cell culture model after exposure to wildtype SBCMV for 24 and 96 hours. Cytokine and chemokine levels 2-fold and higher are included in the table in red text. Plus (+) signs in red and black text indicates changes in $\mathrm{C}-\mathrm{C}$ levels at $24 \mathrm{~h}$ and $96 \mathrm{~h}$. CC levels up or down regulated $\mathrm{CC}$ are indicated by red and blue arrows. Fold change in $\mathrm{C}-\mathrm{C}$ levels are indicated in red text

\begin{tabular}{|c|c|c|c|c|c|c|}
\hline \multirow[b]{3}{*}{$\begin{array}{l}\text { Cytokine/ } \\
\text { Chemokine }\end{array}$} & \multicolumn{4}{|c|}{ Mesangial cells } & \multirow{2}{*}{\multicolumn{2}{|c|}{$\begin{array}{l}\text { Tri-cell model } \\
96 \text { Hours only }\end{array}$}} \\
\hline & \multicolumn{2}{|c|}{24 Hours } & \multicolumn{2}{|c|}{96 Hours } & & \\
\hline & SBCMV-HK & SBCMV-WT & SBCMV-HK & SBCMV-WT & SBCMV-HK & SBCMV-WT \\
\hline $\begin{array}{c}\text { B2- } \\
\text { microglobulin }\end{array}$ & + & + & + & + & ++ & +2.9 -Fold $\downarrow$ \\
\hline Ferritin & + & + & + & + & + & + \\
\hline Complement C3 & + & ++ 3-Fold $\uparrow$ & + & ++2 -Fold $\uparrow$ & + & + \\
\hline IL-6 & + & + & + & + & ND & ND \\
\hline IL-7 & + & ++++12 -Fold $\uparrow$ & + & ++2 -Fold $\uparrow$ & + & ++++13 -Fold $\uparrow$ \\
\hline IL-8 & + & + & + & + & ND & ND \\
\hline RANTES & + & + & + & +++++28 -Fold $\uparrow$ & ++ & +3.2 -Fold $\uparrow$ \\
\hline TNF- $\alpha$ & + & ++2 -Fold $\uparrow$ & + & + & ND & ND \\
\hline GMCSF & + & + & ND & ND & + & + \\
\hline MIP-1 $\alpha$ & + & + & + & + & +++ & ++++9.5 -Fold $\downarrow$ \\
\hline MCP-1 & + & + & ++ & +2 -Fold $\downarrow$ & + & + \\
\hline MMP-3 & + & + & + & + & ND & ND \\
\hline IL-8 & ND & ND & ND & ND & ND & ND \\
\hline VEGF & ND & ND & + & + & + & + \\
\hline Alpha-2 Macrog & ND & ND & ND & ND & + & + \\
\hline IL-1 $\beta$ & ND & ND & ND & ND & + & ++2 -Fold $\uparrow$ \\
\hline Haptoglobin & ND & ND & ND & ND & + & ++++6.3 -Fold $\uparrow$ \\
\hline
\end{tabular}

the upregulation of IL-7 in mesangial cells at $24 \mathrm{~h}$ (12-fold), 96h (2fold) and in the GVU tri-cell model (13-fold) when cells were exposed to wildtype virus compared to cells exposed to heat-killed virus. Serum sIL7R levels have been identified as a specific biomarker of renal disease activity in systemic lupus erythematosus (SLE) [39]. Elevated serum sIL7R levels in SLE patients have been associated with or predict the occurrence of an SLE nephritis flare (reference). A study also found when using by fine-needle aspiration biopsy cultures that IL-7, IL-16 and IL-18 is significantly associated with acute rejection in kidney transplants [40].

RANTES was highly upregulated in mesangial cells exposed to HCMV, and in a report by Corsi et al., they showed patients affected by chronic renal failure as well as kidney-grafted patients affected by chronic transplant dysfunction had plasma levels of RANTES significantly higher than control patients [41]. We observed a 28 -fold increase in RANTES expression in mesangial cells exposed to SBCMV for 96 hours. RANTES upregulation has been associated with chronic renal allograft dysfunction and has been associated with interstitial fibrosis and tubular atrophy [42]. HCMV is a common opportunistic pathogen post lung transplantation. Pulmonary HCMV infection have been associate with reduced long-term survival post-lung transplantation. In a study that examined chemokines dysregulated in lung transplant patients infected with HCMV MCP-1 and RANTES were significantly elevated during pulmonary HCMV and likely contributes allograft dysfunction and a reduction in long-term allograft survival [42]. This study indicates that monitoring CC chemokines like RANTES could have predictive value when assessing HCMV associated post-transplant disease [42].

The increase in TNF- $\alpha$ in mesangial cells at 24 hours could be related to other studies that show RCMV (rat cytomegalovirus) can enhance chronic renal allograft rejection in a rat model associated with tubular apoptosis and increased levels of TNF- $\alpha$-TNF-R1 [43]. In a study by Nordøy et al., renal transplant patients that developed HCMV disease had higher plasma levels TNF- $\alpha$ and IL-10 compared to patients without HCMV disease [44]. During HCMV infection in renal
HCMV Infection in Renal Transplanted Tissue HCMV MIE and pp28

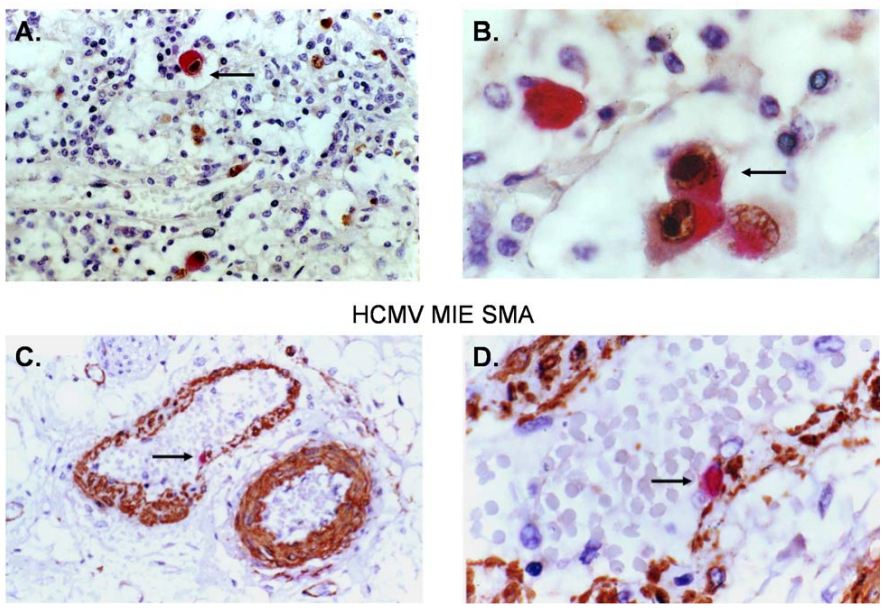

Figure 9. HCMV infection of perivascular cells in a renal transplant patient

Dual labeled immunohistochemical (IHC) staining of renal tissue from a transplant patient is shown. (A) Dual labeled IHC for HCMV MIE (brown stained cells) and HCMV pp28 (red stained cells at 100x total magnification), (B) Dual labeled IHC for HCMV MIE (brown stained cells) and HCMV pp28 (red stained cells at 1000x total magnification), (C) Dual labeled IHC for HCMV MIE (red stained cells) and the pericyte/mesangial cell marker aSMA (brown stained cells at 100x total magnification) (D) Dual labeled IHC for HCMV MIE (red stained cells) and a pericyte marker SMA (brown stained cells at 400x total magnification). Nuclei were stained blue with hematoxylin as a counter stain. All images were taken on a Nikon TE2000S microscope mounted with a charge-coupled device (CCD) camera at 200x magnification unless otherwise indicated. 4',6-diamidino-2- phenylindole (DAPI) was used to stain the nuclei blue

transplant patients it was observed that pp65 antigenemia correlated with increased levels of the chemokines IL-8, MIP-1 $\alpha$, MCP-1 VCAM1, ICAM-1, and L-selectin compared to renal transplant patients without HCMV infection [45].

Luminex analysis of mesangial cells exposed to SBCMV for 96 hours revealed an increase in the expression of $\mathrm{B} 2-\mathrm{m}$, ferritin, complement 
C3, IL-6, IL-7, IL-8, RANTES, VEGF, and MMP-3 compared to mock infected controls (Figure 6A,6B). However, we observed reduced expression of TNF- $\alpha$, MIP- $1 \alpha$, and MCP- 1 , but no change in expression of IL-6 when compared to mock infected controls (Figure 6A,6B).

Finally, after exposure of the GVU tricell model to SBCMV for $96 \mathrm{~h}$ (Figure 9A,9B), we observed increased expression of ferritin, complement C3, alpha-2 macroglobulin, IL-7, IL-8, GMCSF, VEGF, Haptoglobin, and MCP-1, but reduced expression of B2-m, RANTES and MIP-1a (Figure 9A,9B). Haptoglobin was found to be upregulated in the GVC tri-cell culture model exposed to wildtype SBCMV (6.3fold, Table 1). In a study examining urine protein profiling identified alpha-1-microglobulin and haptoglobin as biomarkers for early diagnosis of acute allograft rejection following kidney transplantation (reference). Protein levels haptoglobulin and alpha-1-microglobulin were significantly higher in postoperative urine from renal transplant patients with rejection. This study suggests that haptoglobulin and alpha-1-microglobulin may be reliable biomarkers for rejection [46]. These findings suggest that mesangial cells and GVU cells in the context of HCMV exposure share similar angiogenic and proinflammatory cytokine profiles that could contribute to glomerular inflammation. We confirmed the in vivo significance of mesangial infected with HCMV in renal perivascular cell staining positive for both mesangial markers aSMA and the HCMV MIE gene markers (Figure 10) [47]. Figure 11 represents a model of the mesangial cells exposed to SBCMV only for 24 and $96 \mathrm{~h}$ and illustrates the changes in angiogenic and
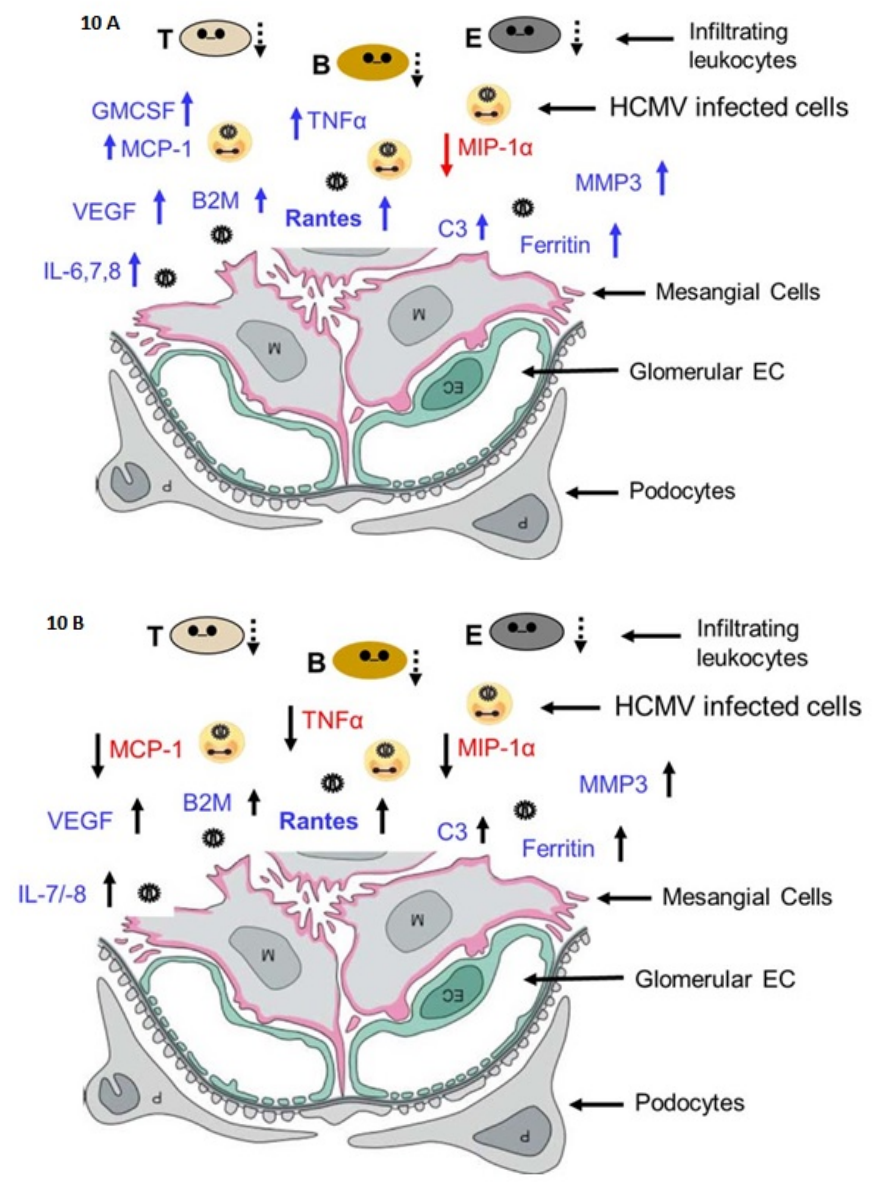

Figure 10. Inflammation model in mesangial cells

Models of SBCMV induction of angiogenic and proinflammatory cytokines in mesangial cells at 24 hours after infection (A) and 96 hours after infection (B)

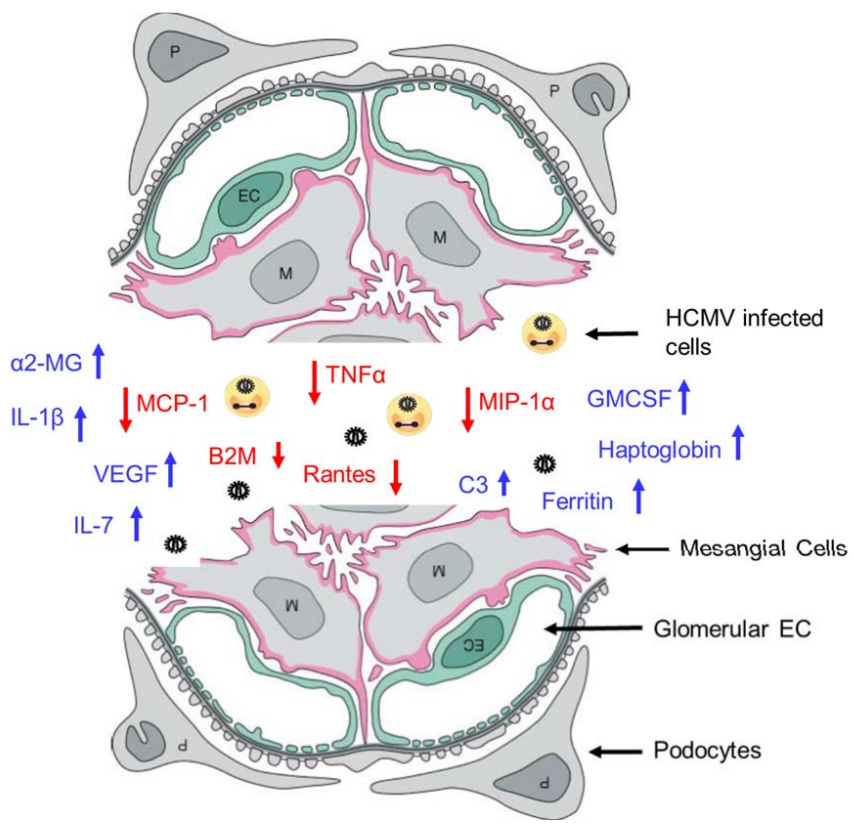

Figure 11. Glomerular inflammation model

A model of the angiogenic and proinflammatory expression profile of the GVU (Glomerular Vascular Unit) tricell culture model 96 hours after SBCMV exposure

proinflammatory cytokines over this interval (Figure 11A,11B). The angiogenic and proinflammatory expression profile we observed in the tricell GVU model would result in glomerular inflammation leading to podocyte injury, mesangial cell activation, and contribute to matrix deposition and glomerulosclerosis. Proinflammatory and angiogenic cytokines induced by HCMV infection of mesangial and GVU cells have been shown to promote reactivation of HCMV from latency [48]. MIP-1 $\alpha$, MCP-1, and IL- 8 are important chemokines in the attraction and activation of granulocytes, $\mathrm{T}$ cells, and monocytes, all of which have been implicated in the dissemination of HCMV and can promote HCMV pathology in renal transplant patients $[49,50]$. We were unable to identify other studies demonstrating the cytokine expression profile of mesangial cells in the context of infection with a clinical isolate of HCMV. Our work appears to be the earliest report to demonstrate that mesangial cells, specialized renal pericytes, are the most permissive cell type in the kidney corpuscle for a clinical isolate of HCMV. We are also among the first to develop a tricell culture model of GVU cells cultivated in a single source medium. As stated in the Materials and Methods Luminex assays were performed using three technical replicates at the same time which represents a limitation in this study that will require further investigation.

\section{Conclusion}

Analysis of the of proinflammatory cytokines and chemokines and their receptors in renal tissue of transplant patients with glomerulonephritis and renal allograft rejection is essential in evaluating the progression of kidney disease, whereas monitoring chemokines in the urine could provide insight into the inflammatory renal microenvironment. The pharmacological regulation of chemokine and chemokine receptor expression may be useful to guide and gauge therapy of kidney diseases.

With further investigation, this study could provide information for the development a biomarker profile for serial screening of renal transplant patients to identify those patients who are at risk for development of HCMV clinical disease in the presence of HCMV prophylaxis. 


\section{Declarations}

\section{Ethics approval and consent to participate}

Written informed consent was obtained from the patient for the publication of this report and any accompanying images are compliant with standard IRB protocol.

\section{Consent for publication}

Not applicable

\section{Availability of data and material}

The authors declare that they used standard commercially software, databases packages, and tool for the data analysis. In addition, the authors declare that they do not have a link to include for the data and materials and that all data and methods of analysis are included in the manuscript and the raw data described will be available for testing by reviewers.

\section{Competing interests}

The authors declare that they have no competing interests.

\section{Funding}

D.J.A. was supported by the Meharry Translational Research Centre (MeTRC), (NIH 5U54MD007593). Research reported in this publication was also supported by the National Centre For Advancing Translational Sciences of the National Institutes of Health under Award Number 3UH2TR000491-02S1 to DJA. W. P. was supported by the NIH MeTRC 5U54MD007593.

\section{Authors' contributions}

DJA conceived and designed the study. DJA, WP, HC, AK, and DMA performed the experiments. DJA drafted the manuscript. All authors have read and approved the final version of the manuscript.

\section{Acknowledgements}

DJA was supported by a Zika Virus Research Startup Award from Meharry Medical College. Research reported in this publication was supported by the NIH (U54MD007593 to DJA). We thank Allison Price for the critical reading of this manuscript. We acknowledge the Meharry Office of Scientific Editing and Publications (supported by NIH grant S21MD000104).

\section{References}

1. Rubin RH (1988) Infection in the renal and liver transplant patient, in clinical approach to infections in the compromised host 2nd ed. New York, Plenum Press.

2. Kotton CN, Fishman JA (2005) Viral infection in the renal transplant recipient. $J \mathrm{Am}$ Soc Nephrol 16: 1758-1774. [Crossref]

3. Smith SR, Butterly DW, Alexander BD, Greenberg A (2001) Viral infections after renal transplantation. Am J Kidney Dis 37: 659-676. [Crossref]

4. Brennan DC (2001) Cytomegalovirus in renal transplantation. J Am Soc Nephrol 12: 848-855. [Crossref]

5. Erdbrügger U, Scheffner I, Mengel M, Schwarz A, Haller H et al. (2015) Long-term impact of CMV infection on allografts and on patient survival in renal transplant patients with protocol biopsies. Am J Physiol Renal Physiol 11: 925-932. [Crossref]

6. Sagedal S, Nordal KP, Hartmann A, Sund S, Scott H, et al. (2002) The impact of cytomegalovirus infection and disease on rejection episodes in renal allograft recipients. Am J Transplant 9: 850-885. [Crossref]

7. Sagedal S, Hartmann A, Nordal KP, Osnes K, Leivestad T, et al. (2004) Impact of early cytomegalovirus infection and disease on long-term recipient and kidney graft survival. Kidney Int 1: 329-337. [Crossref]
8. De Keyzer K, Van Laecke S, Peeters P, Vanholder R (2011) Human cytomegalovirus and kidney transplantation: a clinician's update. Am J Kidney Dis 58: 118-126. [Crossref]

9. Chiasakul T, Townamchai N, Jutivorakool K, Chancharoenthana W, Thongprayoon C, et al. (2015) Risk factors of cytomegalovirus disease in kidney transplant recipients: A single-center study in Thailand. Transplant Proc 8: 2460-2464. [Crossref]

10. Yalci A, Celebi ZK, Ozbas B, Sengezer OL, Unal H, et al. (2015) Evaluation of infectious complications in the first year after kidney transplantation. Transplant Proc 5: 1429-1432. [Crossref]

11. Bataille S, Moal V, Gaudart J, Indreies M, Purgus R, et al. (2010) Cytomegalovirus risk factors in renal transplantation with modern immunosuppression. Transpl Infect Dis 6 480-488. [Crossref]

12. Besbas N, Bayrakci US, Kale G, Cengiz AB, Akcoren Z, et al. (2006) Cytomegalovirusrelated congenital nephrotic syndrome with diffuse mesangial sclerosis. Pediatr Nephrol 5: 740-742. [Crossref]

13. Ortmanns A, Ittel TH, Schnitzler N, Handt S, Helmchen U, et al. (1998) Remission of IgA nephropathy following treatment of cytomegalovirus infection with ganciclovir. Clin Nephrol 6: 379-384. [Crossref]

14. Ustinov JA, Loginov RJ, Mattila PM, Nieminen VK, Suni JI, et al. (1991) Cytomegalovirus infection of human kidney cells in vitro. Kidney Int 40: 954-960. [Crossref]

15. Ustinov J, Mattila P, Häyry P, Lautenschlager I (1992) CMV infection in various cell types of human kidney. Transplant Proc 24: 285. [Crossref]

16. Heieren MH, van der Woude FJ, Balfour HH (1988) Cytomegalovirus replicates efficiently in human kidney mesangial cells. Proc Natl Acad Sci 85: 1642-1646. [Crossref]

17. Busse C, Strubel A, Schnitzler P (2008) Combination of native and recombinant cytomegalovirus antigens in a new ELISA for detection of CMV-specific antibodies. $J$ Clin Virol 2: 137-141. [Crossref]

18. Alcendor DJ, Knobel S (2010) Identifying dysregulated genes induced by Kaposi's sarcoma associated herpesvirus (KSHV). J Vis Exp 14: 43. [Crossref]

19. Alcendor DJ, Charest AM, Zhu WQ, Vigil HE, Knobel SM (2012) Infection and upregulation of proinflammatory cytokines in human brain vascular pericytes by human cytomegalovirus. J Neuroinflammation 9: 95. [Crossref]

20. Saleem MA, O'Hare MJ, Reiser J, Coward RJ, Inward CD, et al. (2002) A conditionally immortalized human podocyte cell line demonstrating nephrin and podocin expression. J Am Soc Nephrol 3: 630-638. [Crossref]

21. Khatua AK, Taylor HE, Hildreth JE, Popik W (2010) Non-productive HIV-1 infection of human glomerular and urinary podocytes. Virology 408: 119-127. [Crossref]

22. Bryant P, Morley C, Garland S, Curtis N (2002) Cytomegalovirus transmission from breast milk in premature babies: does it matter? Arch Dis Child Fetal Neonatal Ed 87: 75-77. [Crossref]

23. Seldin D, Giebisch G. The Kidney 3rd ed. Philadelphia: Lippincortt Williams \& Wilkins.

24. Djoba Siawaya JF, Roberts T, Babb C, Black G, Golakai HJ, et al. (2008) An evaluation of commercial fluorescent bead-based luminex cytokine assays. PLoS One 3: e2535. [Crossref]

25. Reyda S, Tenzer S, Navarro P, Gebauer W, Saur M, et al. (2014) The tegument protein pp65 of human cytomegalovirus acts as an optional scaffold protein that optimizes protein uploading into viral particles. J Virol 88: 9633-9646. [Crossref]

26. Wilkerson I, Laban J, Mitchell JM, Sheibani N, Alcendor DJ (2015) Retinal pericytes and cytomegalovirus infectivity: implications for HCMV-induced retinopathy and congenital ocular disease. J Neuroinflammation 12: 2. [Crossref]

27. Aronoff DM, Correa H, Rogers LM, Arav-Boger R, Alcendor DJ (2017) Placental pericytes and cytomegalovirus infectivity: Implications for HCMV placental pathology and congenital disease. Am J Reprod Immunol e12728. [Crossref]

28. RoachT, Alcendor DJ (2017) Zika virus infection of retinal endothelial cells implications for viral associated congenital ocular disease. J Neuroinflammation 14 43. [Crossref]

29. Rane S, Nada R, Minz M, Sakhuja V, Joshi K (2012) Spectrum of cytomegalovirusinduced renal pathology in renal allograft recipients. Transplant Proc 44: 713-716. [Crossref]

30. Matos AC, Durão MS Jr, Pacheco-Silva A (2004) Serial beta-2 microglobulin measurement as an auxilliary method in the early diagnosis of cytomegalovirus infection in renal transplant patients. Transplant Proc 4: 894-895. [Crossref] 
Popik W (2018) Mesangial cells, specialized renal pericytes and cytomegalovirus infectivity: Implications for HCMV pathology in the glomerular vascular unit and post- transplant renal disease

31. Xue D, He X, Zhou C (2014) Serum hepcidin level correlates with hyperlipidemia status in patients following allograft renal transplantation. Transplant Proc1: 156-159. [Crossref]

32. Fernández-Ruiz M, López-Medrano F, Andrés A, Morales JM, Lumbreras C, et al. (2013) Serum iron parameters in the early post-transplant period and infection risk in kidney transplant recipients. Transpl Infect Dis 6: 600-611. [Crossref]

33. Chatterjee S, Fiala M, Arroyave C, Azen S, Cosgrove D (1982) Complement components in kidney allograft recipients: relationship to cytomegalovirus infection. J Med Virol 3: 237-244. [Crossref]

34. Castro LA, Gokel JM, Thoenes G, Frösner G, Land W, et al. (1983) Renal changes in cytomegalovirus infection. Proc Eur Dial Transplant Assoc 19: 500-504. [Crossref]

35. Andresdottir MB, Assmann KJ, Hilbrands LB, Wetzels JF (2000) Type I membranoproliferative glomerulonephritis in a renal allograft: A recurrence induced by a cytomegalovirus infection? Am J Kidney Dis 2: E6. [Crossref]

36. Salvadori M, Bertoni E (2016) Complement related kidney diseases: Recurrence after transplantation. World J Transplant 4: 632-645. [Crossref]

37. De Vriese AS, Sethi S, Van Praet J, Nath KA, Fervenza FC (2015) Kidney disease caused by dysregulation of the complement alternative pathway: An etiologic approach. J Am Soc Nephrol 12: 2917. [Crossref]

38. Wong L, Moran S, Lavin PJ, Dorman AM, Conlon PJ (2016) Kidney transplant outcomes in familial C3 glomerulopathy. Clin Kidney J 9: 403-407. [Crossref]

39. Lauwerys BR, Husson SN, Maudoux AL, Badot V, Houssiau FA (2014) sIL7R concentrations in the serum reflect disease activity in the lupus kidney. Lupus Sci Med 1: e000036. [Crossref]

40. de Oliveira JG, Xavier PD, Sampaio SM, Tavares IS, Mendes AA (2002) The synthesis by fine-needle aspiration biopsy cultures of IL-7, IL-16 and IL-18 is significantly associated with acute rejection in kidney transplants. Nephron 92: 622-628. [Crossref]
41. Corsi MM, Leone G, Fulgenzi A, Wasserman K, Leone F, et al. (1999) RANTES and MCP-1 chemokine plasma levels in chronic renal transplant dysfunction and chronic renal failure. Clin Biochem 32: 455-460. [Crossref]

42. Weigt SS1, Elashoff RM, Keane MP, Strieter RM, Gomperts BN, et al. (2008) Altered levels of CC chemokines during pulmonary CMV predict BOS and mortality post-lung transplantation. Am J Transplant 8: 1512-1522. [Crossref]

43. Krogerus L, Soots A, Loginov R, Bruggeman C, Lautenschlager I (2008) CMV increases tubular apoptosis through the TNF-alpha-TNF-R1 pathway in a rat model of chronic renal allograft rejection. Transpl Immunol. 3: 232-236. [Crossref]

44. Nordøy I, Müller F, Nordal KP, Rollag H, Lien E, et al. (2000) The role of the tumor necrosis factor system and interleukin-10 during cytomegalovirus infection in renal transplant recipients. J Infect Dis 1: 51-57. [Crossref]

45. Nordøy I, Müller F, Nordal KP, Rollag H, Aukrust P, et al. (2000) Chemokines and soluble adhesion molecules in renal transplant recipients with cytomegalovirus infection. Clin Exp Immunol 2: 333-337. [Crossref]

46. Stubendorff B, Finke S, Walter M, Kniemeyer O, von Eggeling F, et al. (2014) Urine protein profiling identified alpha- 1-microglobulin and haptoglobin as biomarkers for early diagnosis of acute allograft rejection following kidney transplantation. World $J$ Urol 6: 1619-1624. [Crossref]

47. Sarrab RM, Lennon R, Ni L, Wherlock MD, Welsh GI, et al. (2011) Establishment of conditionally immortalized human glomerular mesangial cells in culture, with unique migratory properties. Am J Physiol Renal Physiol 5: 1131-1138. [Crossref]

48. Ho M Cytomegalovirus Biology and infection. New York: Plenum Medical Book Co.

49. Humar A, St Louis P, Mazzulli T, McGeer A, Lipton J, et al. (1999) Elevated serum cytokines are associated with cytomegalovirus infection and disease in bone marrow transplant recipients. J Infect Dis 2: 484-488. [Crossref]

50. Varani S, Landini MP (2011) Cytomegalovirus-induced immunopathology and its clinical consequences. Herpesviridae 2: 6. [Crossref]

Copyright: ( 2018 Popik W. This is an open-access article distributed under the terms of the Creative Commons Attribution License, which permits unrestricted use, distribution, and reproduction in any medium, provided the original author and source are credited. 